Theories \& Applications, the International Edition

Printed Version: (ISSN 2090-5262)

Online Version: (ISSN 2090-5270)

November 2013, Volume 3, No. 3 Pages (36 - 45)

\title{
The Effect of Aqueous and Swiss Ball Exercises on Functional Efficiency and Pain Relief in Lumbar Disk Protrusion Patients
}

\author{
Walid Hussein Hassan*, Ahmed Hassan Nazmy**
}

\section{Introduction}

B ack injuries is one of the most serious injuries which are rapidly develop and cause lower back pain which could disrupt back function. This often causes by excessive use, frequent forward and backward bending and posture deformities, wrong positions and incorrect body mechanics.

Rehabilitation refers to patient treatment and training to restore functional ability in the shortest possible time, using the means of physical therapy that are commensurate with injury type and severity. Rehabilitation exercises are important to speed up individual return to normal life with the same functional and physical efficiency which he was having before the injury as soon as possible (Mervat ElSayed Salama, 1998: p67).

Mohammed al-Najjar (2005, p35) argues that the rehabilitation is to restore function or maintain the infected part so that an individual can perform daily needs easily and conveniently as it works to restore full functionality to the injured person after the injury therefore general rehabilitation varies from sports rehabilitation in class and privacy, Rehabilitation of normal or infected patient depends on how he is able to do the necessary functions and burdens without disorder; while sports rehabilitation aims to develop and functions level for injured person to meet his/her sport activity requirements.

Awareness and belief aqueous exercises benefits is increased; it is now one of the newest ways where aqueous exercises works and preventive

\footnotetext{
* Lecturer, Sports Health Department, Faculty of Physical Education, Minia University, Egypt.

** Lecturer, Sports Training Department, Faculty of Physical Education, Minia University, Egypt.and physical therapy in many treatment or rehabilitation after injury,
}

surgery, general health fitness, weight loss, agility and upgrading fitness level. (Wagdy Mustafa al-Fath,1993: p36)

Aqueous exercises is of the latest and common training methods used at the present time, where is aqueous fitness training is one of favorite training forms and do not need swimming skill and anyone who has a desire to exercise aqueous training can find the right place to perform it. (Abdul Rahman Ibrahim Ragheb, 2009: p9)

Aqueous exercises are known since long; as they used in treatment of muscle weakness, limbs Paralysis, because of their ability to carry objects and resistance; floating on to water allows body to move easily more than on land. (Nadia Mohamed El Sawy Jaafar, 1995: p23)

Khairia Ibrahim El Sokary, Yusuf Dahab, Mohamed Gaber Briqaa (2001, p3) study results declare benefits from aqueous training to higher levels athletes, and rehabilitation and treatment by performing a few times rapid intensity training in aqueous medium, hence gain high fitness fast, which in turn lead to avoid injury and help to return to the natural state (recovery phase) after performing competitions or strong training; or perform aqueous training on successive daily basis and increase time module and the uprising of some motor skills (such as strength, speed, flexibility, endurance.)

Some studies results show that it is specify to define days training and rehabilitation in the water in water rather than spend weekdays in rehabilitation in rehabilitation and physical therapy centers; it works to add more motivation and excitement within injured. (Hatem Hussein, Karim Murad, Adel Mekki,2002:p3) (Mohammed Shamandy Yasin, 2009:p1)

Khairia Ibrahim El Sokary, Yusuf Dahab (2000, p17) study results also confirms that aqueous 
training have positive effect on the physiological responses of "functional efficiency of various body organs, tension indicator for heart rhythm, $t$ lactic acid concentration, pulserate, blood pressure, lungs' vital capacity.

In this regard, Khairia Rl Sokary et al (2001:p15) study results declare that within the physiological benefits of aqueous exercises are : (lowering pulse rate, lowering blood pressure, improving maximum oxygen consumption, improving overall functional efficiency for body organs) .

Aqueous exercises can be performed daily without concern on muscles or joints after injury, it makes rehabilitation more fun than daily rehabilitation outside aqueous medium; if you cannot continue daily walking or running exercise because of e.g. knee injury you can train in water and take advantage of water characteristics to carry objects . (Sherif Mohamed Ahmed, (2006:p10).

Water plays major role in backbone rehabilitation; therefore most doctors advised backbone patients with hydrotherapy; as unique water properties such as weight reducing and physiological benefits which makes the aquatic environment one of the best environments in which to rehabilitate patients with Lumbar Disk Protrusion.

Recently some exercises using tools have been spread; which help to develop physical fitness elements for its practitioners; this are exercises using Swiss ball where originated in Italy and was used in the field of physical therapy, It is called Swiss ball referring for its creators Susan Klein Vogel Bach, in Switzerland and gradually it have been used within fitness programs and then Swiss Ball became one of the famous fitness tools around the world and it is practiced in schools, homes and training centers (Adam Ford, 2005:102).

Better (2004, p185) argues that Swiss ball exercises benefit in increase performance of free exercises on the ground that is, when performance done on rubber ball, resistance to working muscles increase, such as abdominal, back muscles and others, as it is easy to perform exercises with it, strengthen the muscles working and improve individual's internal consistency and inner strength of.

Adam Ford (2005, p23) Peter Twist (2002, p31), Jenny Craig (2006, p185) all agreed that sports scientists at San Dyejua University agreed that Swiss ball exercises increase and improve muscles strength of front and side abdomen and back, and Swiss ball exercises practiced in all ages and is considered also useful in physiotherapy and physical treatment , where untrained women practiced it and it raised their strength level as well as internal stability as it relaxed low back pain they had.

Back injuries are considered of the most serious injuries that develop during certain period and cause lower back pain, which could disrupt back function. This often causes by excessive use, frequent forward and backward bending and posture deformities, wrong positions and incorrect body mechanics (Sameea Khalil Mohammed,: p128).

The lumbar area with its five vertebrae and Intervertebral disks between them form almost $23 \%$ of backbone length; bone vertebrae of this region are characterized by large size and that it have wide, square and horizontal Spinal process. These vertebrae strongly combine together where huge collection of ligaments and muscles help in fixing it; in addition to Intervertebral disks that maintain physiological and motor characteristics for this region.

Individuals suffering injury in lumbar region needs special health and physiological attention when performing any kind of rehabilitation which should fit their health and disease state, because the individual is affected by any load or work straining body, back and backbone muscles (Anwar Fathi Abdullah,2008: pp4-5).

Ahkam Mohammad Ashraf, Khalid Abdul Raouf Ebada (2004, p12) that one of the most important functions of lumbar is to meet the body's need to perform different daily movements in ease and flexibility, and work as a shock absorber because of Intervertebral disks between vertebrae and other which give full flexibility of the trunk and backbone. They also play an important role in posture erectness ND single performance of different movements, and because they are located in body center they 
keep body balance where body's center of gravity pass through them.

Lumbar region pain is not a disease as it is a symptoms produced by many patterns followed by a person in his life; medicine may not succeed in diagnosing reasons for about $85 \%$ from who suffer from this pain symptoms; specially if there is an injury and some pain still retained; most individuals describe this as hurtful and painful (Anwar Fathi Abdullah (2008; p50).

Scientific studies (Anwar Fathi Abdullah (2008), (Khairia Ibrahim El Sokary, Mohamed Gaber Briqaa (2001), (Khairia Ibrahim El Sokary, et al 2001), (Hatem Hussein, Karim Murad, Adel Mekki (2002) referred to many benefits of using aqueous exercise. Scientific studies (Adam Ford (2005), (Cosio-Lima, L., \& Reynold, W. (2003), (Jenny Craig (2006) referred to the importance of using Swiss ball exercises to improve back and abdomen muscle strength in patients with Lumbar Disk Protrusion. In light of what mentioned in these studies; researchers conducted this study, which aims to integrate aqueous exercises with Swiss ball exercises and identify this integration result on efficiency for people with Lumbar Disk Protrusion as to try them could lead to rapid improvement of functional efficiency level and reduce pain degree in patients with Lumbar Disk Protrusion.

\section{Research Importance}

1. Identifying the importance of aqueous exercises for developing physical fitness elements in people with second division Lumbar Disk Protrusion.

2. Identifying the importance of Swiss ball exercises for developing physical fitness elements in people with second division Lumbar Disk Protrusion.

3. Integrating different rehabilitation methods may lead to rapid improvement in persons with Lumbar Disk Protrusion.

\section{Research Objectives}

This research aims to identify the effect of aqueous exercises and Swiss ball exercises on functional efficiency level and pain level in Lumbar Disk Protrusion patients through identifying:

1. Muscle strength level in second division Lumbar Disk Protrusion patients.

2. Flexibility level in second division Lumbar Disk Protrusion patients.

3. Pain relief in second division Lumbar Disk Protrusion patients.

\section{Research Hypotheses}

There are statistically significant differences between pre and post measurements means in :

1. Muscle strength level in favor of postmeasurements or experimental group

2. Flexibility level in favor of postmeasurements or experimental group

3. Pain relief in favor of post-measurements or experimental group

\section{Research Terminology}

\section{Swiss Ball}

"A rubber ball filled with high pressure air and have several colors and dimensions; its diameter range between $(55$ to $95 \mathrm{~cm}$ ); that is to fit practitioners; whether children, youth, women, or elderly" (20).

\section{Aqueous}

It is a medium differed from what individual gets used in terms of its nature and resistors against body, which requires individual adaptation with it. (Nadia Mohamed El Sawy Jaafar (1995; p6)

\section{Research Plan and Procedures}

\section{Research Methodology}

Researchers used experimental approach with pre and post measurements design or one group as it suits research nature and to fulfill research goals

\section{Research Community}

The research community has been selected from second division Lumbar Disk Protrusion injured in Minya governorate who get there treatment in 
medical rehabilitation unit in Minya Sports Club and aged (40-50) years. Thus research community were (20) injured.

\section{Research Sample}

Sample was selected intentionally from second division Lumbar Disk Protrusion injured in Minya governorate who get there treatment in medical rehabilitation unit in Minya Sports Club, (10) patients were selected for main study, (5) patients were selected for pilot study. (5) Patients were excluded as they are not meeting sample terms.

\section{Research sample selection terms}

- Injured should not be following any rehabilitation program.

- Regularity in attending rehabilitation program duration research period.

- Exclusion of people with chronic diseases such as high blood pressure and diabetes.

- Not taking any pain relief drugs.

- Patient approval to undergo the proposed rehabilitation program.

Table (1)

Average, median, standard deviation and skewness coefficient for Muscle Strength, Flexibility level and Pain level of research experimental group $(n=10)$

\begin{tabular}{|c|c|c|c|c|c|c|}
\hline Variables & Measurements & $\begin{array}{c}\text { Measuring } \\
\text { unit }\end{array}$ & Average & Median & $\begin{array}{c}\text { Standard } \\
\text { Deviation }\end{array}$ & $\begin{array}{c}\text { Skewness } \\
\text { factor }\end{array}$ \\
\hline \multirow{3}{*}{$\begin{array}{c}\text { Muscle } \\
\text { Strength }\end{array}$} & Back muscle strength & $\mathrm{Kg}$ & 35.2 & 1.79 & 2.79 & 1.4 \\
\cline { 2 - 7 } & Abdomen Muscle strength & $\mathrm{Kg}$ & 22.5 & 4.32 & 0.17 & -0.36 \\
\cline { 2 - 7 } & Legs Muscle strength & $\mathrm{Kg}$ & 39.2 & 2.13 & 0.09 & -0.48 \\
\hline \multirow{3}{*}{ Flexibility level } & Front backbone flexibility & $\mathrm{Cm}$ & 10.9 & 10.5 & 1.37 & -0.88 \\
\cline { 2 - 7 } & Back backbone flexibility & $\mathrm{Cm}$ & 15.2 & 15 & 0.47 & 1.36 \\
\cline { 2 - 7 } & Right backbone flexibility & $\mathrm{Cm}$ & 47.5 & 47.2 & 0.57 & -1.38 \\
\cline { 2 - 7 } & Left backbone flexibility & $\mathrm{Cm}$ & 46.9 & 46.6 & 0.18 & -0.93 \\
\hline Pain level & Pain degree level & Mark & 6.5 & 6.2 & 2.11 & 1.01 \\
\hline
\end{tabular}

Table (1) results reveal that skewness coefficients for Muscle Strength, flexibility level and Pain level are between $( \pm 3)$, which refers to normal distribution for research sample in these variables

\section{Data Collecting Tools}

\section{Questionnaires used:}

1. Experts' questionnaire about tests used in the research. (appendix 3)

2. Experts' questionnaire about the content of proposed training program )aqua - Swiss ball) for experimental group. (appendix 3)

\section{Tests used in the research:}

In light of what mentioned in the previous studies Through what was seen by researchers from previous studies : Anwar Fathi Abdullah (2008), Basem Mohamed Khalil (2009), Mohammed El Sayed Mursi (2009), Muntasir Ibrahim Torfa (2004) ; and as per experts opinion (appendix 3) following tests have been selected to be used in this research

1. (VAS) test to measure pain degree by visual gauge. (Appendix 2)
2. Trunk forward bent test to measure backbone front flexibility. (Appendix 2)

3. Trunk backward bent test to measure backbone back flexibility. (Appendix 2)

4. Trunk side (left-right) bent test to measure backbone side flexibility. (Appendix 2)

5. Dynamometer test for measuring leg muscles' strength. (Appendix 2)

6. Dynamometer test for measuring back muscles' strength. (Appendix 2)

P-198 Combo Abdominal Back Extension w/ ROM test to measure abdomen muscles'

\section{Devices and tools used:}

- Restameter for measuring height and weight.

- Swiss balls (85) cm diameter.

- Dynamometer for measuring back and abdomen muscle strength. (Appendix 2)

- P-198 Combo Abdominal Back Extension w/ ROM for measuring abdomen muscles' strength. (Appendix 2)

- Tutorial Pool 
- Measure tape

- Scaled wooden box to measure backbone flexibility. (Appendix 2)

Digital clock to determine each exercise time.

\section{Pilot study}

Researchers depended on pilot study results in determine implementation methods of proposed rehabilitation program for developing muscle strength level and flexibility. Pilot study carried out in the period from may 11th, 2012 to May 15th , 2012 on pilot study sample of (5) injured not in the study sample.

Proposed Rehabilitation Program: (appendix 5)

\section{Program Objective:}

Identify the effect of aqueous exercises and Swiss ball exercises on functional efficiency level and pain level in Lumbar Disk Protrusion patients

\section{Program developing bases:}

Exercises content should suit study sample who are injured with Lumbar Disk Protrusion

Considering individual differences among injured persons.

Program should be flexible so that it can be modified if necessary

Program should achieve its objective which is improving functional efficiency and reduce the degree of pain in patients with a sample search.

Considering diversity principle in exercises inside rehabilitation; so patients do not feel bored and monotony due to the application of the proposed rehabilitation program.

\section{Program content:}

Ahkam Mohammad Ashraf, Khalid Abdul Raouf Ebada (2004), Basem Mohamed Khalil (2009) , Khairia Ibrahim El Sokary et al (2001), Samah Abd al-Raziq Attia (2010), Mohammed al-Najjar Tawfiq (2005) argued that Swiss ball exercises should be used in rate of $(1: 2)$ for aqua training and to take advantage water properties in carrying objects, especially at beginning of proposed rehabilitation; due to performance difficulty that patient suffer. In light of this rehabilitation program developed and presented to sports injuries, medicine rehabilitation and rheumatology experts (appendix 1) in order to ensure its application suitability to research sample and its association and effect on research variables as well as determine the total program period and number of weekly rehabilitation units and each unit time. Rahabilitation program amended as per experts opinion

\section{Daily rehabilitation unit parts:}

\section{Warm-up: (15) minutes}

The aim is all body preparation for the main part.

II. Secondly, the main part: (60) minutes.

\section{Aqua exercises (40) minutes Swiss ball exercises (20) minutes}

It is the most important part because it is where program objective could be achieved, there were varied intensity exercises to restore motion range; also exercises to develop muscle strength for muscles working on backbone. Rehabilitation unit begins aqueous exercises to take advantage of water properties to reduce pain degree and easily perform exercises Due to water nature in carrying objects for (40) minutes. This followed by Swiss ball exercises; in first part performance from stability and balance; then performance from movement. This group exercises is for (20) minutes.

\section{Recovery and cool down: (15) minutes}

Aims to return the body to its natural state

\section{Experiment performance steps}

\section{Pre- measurements:}

Researchers conducted pre- measurements for research sample in physical variables (muscle strength - flexibility) and pain degree on May 15th, 2012 in Minya athletic stadium.

\section{Main experiment:}

Proposed rehabilitation program using aqueous and Swiss Ball exercises implemented on injured experimental sample for (3) months (12) weeks, three units weekly in the period from May 16th, 2012 to September 19th, 2012.(in Saturday, Monday and Wednesday).

\section{Research Steps:}

- Program implementation period = three months $=(12$ weeks $)$. 
- Weekly Rehabilitation units $=3$ units

- Program Rehabilitation units = 3units $\mathrm{x} 12$ weeks $=36$ units

- Rehabilitation unit time $=90$ minutes

- Proposed program content included simple exercise to develop muscle strength and flexibility in research sample.

- Training on performance in light of scientific bases of sports rehabilitation.

- Considering ease of aqua and Swiss ball exercises to suit research sample, especially they are injured.

\section{Post- measurements:}

Post - measurements were taken in the same arrangements as pre-measurements and held on September 20th, 2012.

Statistical measurements:

The researchers used the following statistical tests, factors and programs:

1. Mean

2. T. Test

3. Standard deviation

4. Improvement ratio test

5. Skewness coefficient

6. SPSS. Statestical package

\section{Results and discussion}

\section{Results}

Table (2)

Differences significance between pre and post measurements for experimental sample in physical variables (muscle strength)

$n=10$

\begin{tabular}{|c|c|c|c|c|c|c|c|c|c|c|}
\hline \multirow{2}{*}{ Tests } & \multirow{2}{*}{ Variables } & \multirow{2}{*}{$\begin{array}{c}\text { Measurement } \\
\text { unit }\end{array}$} & \multicolumn{2}{|c|}{$\begin{array}{c}\text { Pre- } \\
\text { measurement }\end{array}$} & \multicolumn{2}{|c|}{ Post-measurement } & \multirow[t]{2}{*}{$\begin{array}{c}\text { Mean } \\
\text { differences }\end{array}$} & \multirow[t]{2}{*}{$\begin{array}{l}\text { Improvement } \\
\text { ratio }\end{array}$} & \multirow{2}{*}{$\begin{array}{c}\mathrm{T} \\
\text { value }\end{array}$} & \multirow{2}{*}{ Significance } \\
\hline & & & Mean & $\begin{array}{c}\text { Standard } \\
\text { Deviation }\end{array}$ & Mean & $\begin{array}{c}\text { Standard } \\
\text { Deviation }\end{array}$ & & & & \\
\hline \multirow{3}{*}{$\begin{array}{l}\text { Muscle } \\
\text { Strength }\end{array}$} & $\begin{array}{l}\text { Back muscle } \\
\text { strength }\end{array}$ & $\mathrm{Kg}$ & 35.2 & 2.79 & 42.5 & 2.5 & 7.2 & $17.10 \%$ & $1.08 *$ & significant \\
\hline & $\begin{array}{l}\text { Abdomen Muscle } \\
\text { strength }\end{array}$ & $\mathrm{Kg}$ & 22.5 & 0.17 & 27.5 & 0.5 & 5 & $18.10 \%$ & $2.09^{*}$ & significant \\
\hline & $\begin{array}{l}\text { Legs Muscle } \\
\text { strength }\end{array}$ & $\mathrm{Kg}$ & 39.2 & 0.09 & 44.5 & 0.62 & 5.3 & $11.90 \%$ & $3.04 *$ & significant \\
\hline
\end{tabular}

\footnotetext{
$T$ significance at $0.05=2.14$
}

Table (2) results revealed that there were experimental group in physical variables level statistically significant differences at 0.05 level (muscle power) where $\mathrm{T}$ calculated values were between pre and post measurements for higher that $\mathrm{T}$ significance at (0.05).

Table (3)

Differences significance between pre and post measurements for experimental sample in flexibility level $n=10$

\begin{tabular}{|c|c|c|c|c|c|c|c|c|c|c|}
\hline \multirow{2}{*}{ Tests } & \multirow{2}{*}{ Variables } & \multirow{2}{*}{$\begin{array}{c}\text { Measurement } \\
\text { unit }\end{array}$} & \multicolumn{2}{|c|}{$\begin{array}{c}\text { Pre- } \\
\text { measurement }\end{array}$} & \multicolumn{2}{|c|}{ Post-measurement } & \multirow[t]{2}{*}{$\begin{array}{c}\text { Mean } \\
\text { differences }\end{array}$} & \multirow[t]{2}{*}{$\begin{array}{l}\text { Improvement } \\
\text { ratio }\end{array}$} & \multirow{2}{*}{$\begin{array}{c}\mathrm{T} \\
\text { value }\end{array}$} & \multirow{2}{*}{ Significance } \\
\hline & & & Mean & $\begin{array}{c}\text { Standard } \\
\text { Deviation }\end{array}$ & Mean & $\begin{array}{l}\text { Standard } \\
\text { Deviation }\end{array}$ & & & & \\
\hline \multirow{4}{*}{$\begin{array}{c}\text { Flexibility } \\
\text { level }\end{array}$} & $\begin{array}{l}\text { Front backbone } \\
\text { flexibility }\end{array}$ & $\mathrm{Cm}$ & 10.6 & 1.17 & 12.6 & 1.01 & 2 & $15.80 \%$ & $3.11 *$ & significant \\
\hline & $\begin{array}{c}\text { Back backbone } \\
\text { flexibility }\end{array}$ & $\mathrm{Cm}$ & 15.7 & 0.4 & 17.2 & 0.68 & 1.5 & $8.70 \%$ & $3.65^{*}$ & significant \\
\hline & $\begin{array}{l}\text { Right backbone } \\
\text { flexibility }\end{array}$ & $\mathrm{Cm}$ & 47.9 & 0.46 & 43.2 & 0.65 & 4.7 & $10.80 \%$ & $3.22 *$ & significant \\
\hline & $\begin{array}{l}\text { Left backbone } \\
\text { flexibility }\end{array}$ & $\mathrm{Cm}$ & 46.3 & 0.17 & 42.5 & 0.41 & 3.8 & $8.90 \%$ & $3.11 *$ & significant \\
\hline
\end{tabular}

T significance at $0.05=2.14$

Table (3) results revealed that there were statistically significant differences at 0.05 level between pre and post measurements for experimental group in flexibility level where $\mathrm{T}$ calculated values were higher that $\mathrm{T}$ significance at (0.05). 
Table (4)

Differences significance between pre and post measurements for experimental sample in flexibility level $n=10$

\begin{tabular}{|c|c|c|c|c|c|c|c|c|c|c|}
\hline \multirow{2}{*}{ Tests } & \multirow{2}{*}{ Variables } & \multirow{2}{*}{$\begin{array}{c}\text { Measurement } \\
\text { unit }\end{array}$} & \multicolumn{2}{|c|}{$\begin{array}{c}\text { Pre- } \\
\text { measurement }\end{array}$} & \multicolumn{2}{|c|}{ Post-measurement } & \multirow[t]{2}{*}{$\begin{array}{c}\text { Mean } \\
\text { differences }\end{array}$} & \multirow[t]{2}{*}{$\begin{array}{l}\text { Improvement } \\
\text { ratio }\end{array}$} & \multirow{2}{*}{$\begin{array}{c}\mathrm{T} \\
\text { value }\end{array}$} & \multirow{2}{*}{ Significance } \\
\hline & & & Mean & $\begin{array}{c}\text { Standard } \\
\text { Deviation }\end{array}$ & Mean & $\begin{array}{c}\text { Standard } \\
\text { Deviation }\end{array}$ & & & & \\
\hline $\begin{array}{l}\text { Pain } \\
\text { level }\end{array}$ & $\begin{array}{c}\text { Pain } \\
\text { degree } \\
\text { level }\end{array}$ & Mark & 6.5 & 2.11 & 3.2 & 1.2 & 3.3 & $103.10 \%$ & $3.22 *$ & significant \\
\hline
\end{tabular}

T significance at $0.05=2.14$

Table (4) results revealed that there were statistically significant differences at 0.05 level between pre and post measurements for experimental group in pain level where $\mathrm{T}$ calculated values were higher that $\mathrm{T}$ significance at (0.05).

\section{Discussion}

First hypothesis states that "There are statistically significant differences between pre and post measurements means in muscle strength level in favor of post-measurements or experimental group".

To validate this hypothesis; researchers compared results of pre and post results for experimental sample and Table. (2) shows that there were statistically significant differences at 0.05 level between pre and post measurements of experimental group in muscle strength level.

This is in consistent with what referred by Khairia Ibrahim El Sokary and Mohamed Gaber Briqaa "where they confirmed that aqueous exercises have multiple physical and physiological benefits, and within its physical benefits is developing muscle strength and it have multiple physiological and physical benefit which help all professionals in the areas of rehabilitation and training.

This is also supported by results of Samah Abd al-Raziq Attia (2010) study ; which arrived to that aqueous training has positive effect on physiological and physical responses for back pain and hemiplegia patients; where it was better in its positive effect than rehabilitation exercises and electrical stimulation due to water properties in carrying objects, and also in improving movement range

These results also are consistent with results of Samah Abd al-Raziq Attia (2010); Abdul Rahman Ibrahim Ragheb (2009), Mohammed El Sayed Mursi (2009), and Mohammed
Shamandy Yasin (2009) studies' results which proofed that aqueous training contribute in improvement of some physical variables (muscle strength).

In this regard Peter Twist (2002, p147) argued that practicing motor program work to strengthen motor muscle group supporting lumbar area and helps to relieve lower back pain.

Adam Ford (2005, p23) states that Swiss ball exercises could be practiced by all ages and abilities; it is useful in physiotherapy, psychological and physical therapy. Untrained ladies have practiced it and raised their strength level; and also removed lower back pain.

Through what mentioned above it is clear that there was improvement in physical variables ( muscle strength) for legs, back and abdomen muscles in patients with 2nd division Lumbar Disk Protrusion (experimental sample).

The second hypothesis states that "There are statistically significant differences between pre and post measurements means in flexibility level in favor of post-measurements or experimental group"

To validate this hypothesis; researchers compared results of pre and post results for experimental sample. Table. (3) shows that there were statistically significant differences at 0.05 level between pre and post measurements of experimental group in flexibility level.

Researchers return this to use aqueous and Swiss ball exercises as it is considered part of physical fitness development programs for specific body parts and within their benefits development of many physical abilities like flexibility, also they work on tightening muscles working and strengthen it, improve individual's inner consistency and strength. As well as when using Swiss Ball and due to its rubber 
characteristic more resistant will be on working muscles especially abdominal and back around backbone.

In this regard Peter Twist (2002, p147) argued that practicing motor program work to strengthen motor muscle group supporting lumbar area and increase backbone flexibility in all directions which helps to relieve lower back pain.

This results is in agreement with Mahmoud Farouk Sabra (2006) Adam Ford (2005), Better, U. (2004), Cosio-Lima, L., \& Reynold, W. (2003), and Stanton,R,Reabum P, (2004):" study results which all proofed the positive effect of Swiss ball excercises in increasing backbone flexibility level

Through what mentioned above it is clear that there was improvement in front, back and side backbone flexibility in patients with 2nd division Lumbar Disk Protrusion (experimental sample).

The third hypothesis states that "There are statistically significant differences between pre and post measurements means in pain level in favor of post-measurements or experimental group"

To validate this hypothesis; researchers compared results of pre and post results for experimental sample. Table. (4) shows that there were statistically significant differences at 0.05 level between pre and post measurements of experimental group in pain level.

In this regard Anwar Fathi Abdullah (2008, p99) argued that of the main advantages of hydrotherapy is to reduce trunk parts movement, distribute motion and strengthen control in lumbar vertebrae, as water increase patient's control ability and reduces repeated movement errors in exercises on land.

This result is in consistent with Anwar Fathi Abdullah (2008), Basem Mohamed Khalil (2009), Samah Abd al-Raziq Attia (2010), and Muntasir Ibrahim Torfa (2004) study results which proofed that use of aqueous and Swiss Ball exercises have positive impact on improving muscle strength and flexibility level in Lumbar Disk Protrusion patients and reduce pain within them
Through what mentioned above it is clear that there were statistically dsignificat difference between pre and post test for experimental group undergone aqueous and swiss ball exercises program; where there were improvement in leg, back, and abdomen smuscles' strength; front, back and side backbone flexibility; and pain level in patients with 2nd division Lumbar Disk Protrusion (experimental sample).

\section{Conclusions}

Within limits of research objective, in light of its hypothesis and methodology and through statistical analysis researchers reached the following conclusions: -

1. Aqueous and Swiss ball exercises rehabilitation program has positive effect in increasing muscle strength of muscles working around backbone in patients with 2 nd division Lumbar Disk Protrusion

2. Aqueous and Swiss ball exercises rehabilitation program has positive effect in increasing backbone flexibility in patients with 2nd division Lumbar Disk Protrusion

3. Aqueous and Swiss ball exercises rehabilitation program has positive effect in improving pain level in patients with 2nd division Lumbar Disk Protrusion

\section{Recommendations}

In light of research results researchers recommend the following:

1. Using proposed Aqueous and Swiss ball exercises program in rehabilitation of patients with 2nd division Lumbar Disk Protrusion

2. Conducting similar studies and research using aqueous and Swiss ball exercises on other injuries and different samples.

3. Using the proposed rehabilitation program as a guide in treatment of Lumbar Disk Protrusion with its all levels.

\section{References}

1. Abdul Rahman Ibrahim Ragheb (2009) "training program using aqueous medium for 
development of muscular strength and its impact on the performance level of basic strikes for juniors in tennis, Master Thesis, Faculty of Physical Education, University of Tanta. (in Arabic language)

2. Adam Ford (2005): Swiss Ball Abs\& core stability. Regian 1st edi. USA, California.

3. Ahkam Mohammad Ashraf, Khalid Abdul Raouf Ebada (2004) "Effect of proposed rehabilitation program for back convexity for females aged of (50-60) years with fragilitas ossium, Journal of Physical Education and Sports, Faculty of Physical Education, Menoufia University. (in Arabic language)

4. Anwar Fathi Abdullah (2008): "The impact of proposed aqua rehabilitation program on work efficiency of nerve roots pressurized as a result of first class Lumbar Disk Protrusion" Master thesis, Faculty of Physical Education, Helwan University. (in Arabic language)

5. Basem Mohamed Khalil (2009) "The effect of proposed aqua rehabilitation program accompanied with therapeutic exercises on lower back pain patients after joint replacement surgery: Master Thesis, Faculty of Physical Education, University of Helwan. (in Arabic language)

6. Better, U. (2004): The best abdominal Exercises you have heard of Grey Lake Inc. Box 342 Illinois USA

7. Cosio-Lima, L., \& Reynold, W. (2003):" Effects of physic ball and conventional floor exercises on early phase adaptations in back and Abdominal core stability and balance in women ", Strength ConRes

8. Hatem Hussein, Karim Murad, Adel Mekki (2002): "The effect using certain aqueous exercises on developing shooting motor skills in handball, scientific conference "strategies of selecting selection and preparing sports talents in the light of technological development and the information revolution, Alexandria. (in Arabic language)

9. James Rainville\& Carol hartigon(2004)": Exercise as a Treatment ", The Spine Journal p106-115.

10. Jenny Craig (2006):"Weight Fitness Exercise Balls", Gregory 1st, California, USA.
11. Khairia Ibrahim El Sokary, Mohamed Gaber Briqaa (2001): "The concept of training in aqueous media and its application in team and individual sports, the International Scientific Conference of Sports and globalization, Faculty of Physical Education for Men, Helwan University, 2000. (in Arabic language)

12. Khairia Ibrahim El Sokary, Yusuf Dahab, Mohamed Gaber Briqaa (2001): "Introduction to biological responses to highlight running training outside and inside the deep water to standardize functional efficiency of sports woman, the International Conference on Sport and globalization, Volume III, Faculty of Physical Education for Men, University of Helwan. (in Arabic language)

13. Mahmoud Farouk Sabra (2006) "The effect of rehabilitation exercises program on some cases of Lumbar Disk Protrusion, Ph.D. thesis, Faculty of Physical Education, University of Assiut. (in Arabic language)

14. Mavis Berridge, Graham Ward;(1998) International Perspectives on Adapted Physical, Activities ,Fry, G.Berra K,U.s.A,

15. Mervat ElSayed Salama (1998): studies on sports medicine problems, Elesheaa Elfania library, Alexandria.(in Arabic language)

16. Mohamed Sobhy Hassanein (2001): Measurement and Evaluation in physical education and sports, first vol., 1st ed. , Dar AlFekr AlArabi, Cairo.

17. Mohammed al-Najjar Tawfiq (2005): "The impact of rehabilitative exercises on functional stability of the ankle after lateral ligament rupture", unpublished Master thesis, faculty of Physical Education for Men, Helwan University. (in Arabic language)

18. Mohammed El Sayed Mursi (2009), " rehabilitation program using Aqua treatment on functional efficiency of hip joint after replacement surgery," Master Thesis, Faculty of Physical Education, University of Tanta. (in Arabic language)

19. Mohammed Shamandy Yasin (2009): "The impact of using aqueous and sand environment exercises on some physiological, physical variables and result records for 1,500 meters runners" comparative study, Master Thesis, 
Faculty of Physical Education, University of Assiut. (in Arabic language)

20. Muntasir Ibrahim Torfa (2004) "The effect of using proposed aqua training program on rehabilitation of lumbar ligaments patients, scientific research publication, theories and applications journal, the Faculty of Physical Education for Men, Alexandria University. (in Arabic language)

21. Nadia Mohamed El Sawy Jaafar (1995): " development of some special physical apabilities using aqueous exercises and its impact on the performance level of some basic skills in handball, Master Thesis, Faculty of Physical Education, University of Zagazig (in Arabic language)

22. Peter Twist(2002):Human Kinetics in "Strength Ball Training" .Lorne, Pen .USA .

23. Samah Abd al-Raziq Attia (2010), " Comparative study of the impact of hydrokinetic; ozone and electrical stimulation rehabilitation programs in improving efficiency of motor and nerve systems for hemiplegia patients, $\mathrm{PhD}$ thesis, Faculty of Physical
Education for Girls, Zagazig University. (in Arabic language)

24. Sameea Khalil Mohammed (2007), "sports injuries", Iraqi International Academy. (in Arabic language)

25. Sherif Mohamed Ahmed (2006): "Sport practice and physical activity as a life style for elder peoples , analytical study ", Ph.D. thesis, Faculty of Physical Education, University of Helwan. (in Arabic language)

26. Stanton,R,Reabum P, (2004):"The Effect of short-term Swiss Ball training on core stability and running economy",J Strength and Conditioning Research, Aug.

27. Wagdy Mustafa al-Fath (1993): "The impact of recreational aqueous exercises program on physiological and psychological variables within students of the Faculty of Physical Education, University of Bahrain, scientific journal of Physical Education and Sports, University of Helwan. (in Arabic language)

28. Williams JW, Jr\& Other(1995):"Measuring shoulderfunction with the Shoulder Pain and Disability Index". J Rheumatol. ;22.p727-732 